\title{
Short distance pollen dispersal and low genetic diversity in a subcanopy tropical rainforest tree, Fontainea picrosperma (Euphorbiaceae)
}

\author{
Elektra L. Grant ${ }^{1} \cdot$ Gabriel C. Conroy $^{1} \cdot$ Robert W. Lamont $^{1} \cdot$ Paul W. Reddell $^{2} \cdot$ Helen M. Wallace ${ }^{1}$. \\ Steven M. Ogbourne ${ }^{1}$
}

Received: 18 December 2018 / Revised: 28 March 2019 / Accepted: 24 April 2019 / Published online: 11 May 2019

(c) The Genetics Society 2019

\begin{abstract}
Gene flow via pollen movement affects genetic variation in plant populations and is an important consideration in plant domestication. Fontainea picrosperma is a subcanopy rainforest tree that is of commercial interest because it is the source of tigilanol tiglate, a natural product used for the treatment of solid tumors. We identify patterns of pollen-mediated gene flow within natural populations of $F$. picrosperma and estimate genetic parameters and genetic structure between adult and juvenile groups using microsatellite markers. Our results show pollination events occur over much shorter distances than reported for tropical canopy species. At least $63 \%$ of seeds are sired by male trees located within $30 \mathrm{~m}$ of the mother. On average, $27 \%$ of the local male population contributed to successful reproduction of $F$. picrosperma with most fathers siring a single seed, however, the contributions to reproduction were uneven. Larger male trees with more flowers had greater reproductive success than those with less flowers $(P<0.05)$. There were comparatively low levels of genetic variation across the species ( $H_{\mathrm{E}}=0.405$ for adult trees and 0.379 for juveniles) and we found no loss of genetic diversity between adult and juvenile trees. Short distance pollen flow and low genetic diversity is theoretically a prelude to genetic impoverishment, however $F$. picrosperma has persisted through multiple significant climatic oscillations. Nevertheless, the remaining low genetic diversity is of concern for domestication programs which require maximal genetic diversity to facilitate efficient selective breeding and genetic improvement of this commercially significant species.
\end{abstract}

\section{Introduction}

Genes move within and among plant populations through pollen and seed dispersal as well as physical movement of vegetative plant material. Plant mating patterns in tropical rainforests, mediated by gene movement of pollen, is an important determinant in the level of genetic variation within and among populations. Gene flow can counteract the potentially detrimental effects of genetic drift and may

Supplementary information The online version of this article (https:// doi.org/10.1038/s41437-019-0231-1) contains supplementary material, which is available to authorized users.

Steven M. Ogbourne

sogbourn@usc.edu.au

1 GeneCology Research Centre, University of the Sunshine Coast, Sippy Downs, QLD, Australia

2 EcoBiotics Limited, Yungaburra, QLD, Australia be a source of new alleles within populations (Burczyk et al. 2004). However, when gene flow is restricted, inbreeding or biparental inbreeding (mating with close relatives) can occur and ultimately lead to a loss of genetic diversity, directional selection and genetic drift (Ellstrand and Elam 1993). Tropical forest ecosystems are experiencing high rates of habitat destruction and forest fragmentation that can negatively impact on genetic variation within species (Bradshaw et al. 2009; Eckert et al. 2010). The modification of habitat can disrupt natural patterns of gene flow by creating environments that are stressful for pollinator survival and activity (Eckert et al. 2010). Though, the impacts to mating patterns vary between species and context (Hamrick 2004; Lowe et al. 2015) and can be affected by a species life history, reproductive biology and the mobility of pollinators (Breed et al. 2015; Rymer et al. 2015; Vinson et al. 2015).

Most woody tropical rainforest species are strongly outcrossed and rely on insects for pollination (Bawa 1992; Ollerton et al. 2011). The density of flowering conspecifics, 
including factors such as spatial distribution and the distance to the nearest pollen source can influence pollinator foraging behavior (House 1993; Ghazoul 2005). Commonly, pollinator flight distances tend to increase with lower plant densities and decrease when flowering plants exhibit a clumped distribution or occur at high densities (House 1992; Stacy et al. 1996; Hardy et al. 2006; Born et al. 2008; Ashley 2010; Silva et al. 2011; Naoki et al. 2012; Duminil et al. 2016). This is because near-neighbor mating increases the foraging economy of the pollinating insect by maximizing the net energy gained by the pollen or nectar source (Levin and Kerster 1974; Degen and Sebbenn 2016). There is strong empirical evidence that suggests that tropical canopy species with low population densities exhibit long distance pollen dispersal (Akihiro et al. 2000; Kenta et al. 2004; Ward et al. 2005; Hardesty et al. 2006; Born et al. 2008; Carneiro et al. 2009; Ottewell et al. 2012; Monthe et al. 2017). While there are relatively few studies describing gene flow within understorey species, pollen has been found to disperse shorter distances in tropical or subtropical woody taxa, particularly in species with high local densities (Lasso et al. 2011; Castilla et al. 2016; Hahn et al. 2017).

Pollen-mediated gene flow, measured in terms of successful reproduction, is affected by other density measures such as phenology and its synchronicity, as well as the size of the nearest pollen source (O'Connell et al. 2018). Variation in these factors influence pollination distances, pollen dispersal patterns and levels of genetic isolation (Castilla et al. 2017). For example, large male trees (measured by species specific differences in diameter at breast height) can contribute disproportionately to seed production (Hoebee et al. 2007; Naoki et al. 2012; Tambarussi et al. 2015; Monthe et al. 2017; Younginger et al. 2017). Thus, the size of nearest pollen source becomes important because a large but more distant male may contribute more pollen than a smaller, closer one. Determining variations in male fecundity within populations is important because mating partners can influence genetic diversity and population fitness (Breed et al. 2012a). Unfit combinations of pollen and ovules are more likely to occur in offspring when fewer males contribute to reproduction. With more mating partners, there is a smaller probability that recessive deleterious alleles will be involved in reproduction (Breed et al. 2012b).

Historical gene flow can be inferred through the distribution of genetic diversity between generations of individuals (Slatkin 1987; Young et al. 1996; Lowe et al. 2005). Genetic diversity and differentiation between age cohorts within populations are critical parameters that impact population genetics and structure, particularly in landscapes where habitat has been modified. This is because altering the number of reproductive individuals in the population can negatively impact genetic diversity and inbreeding levels in progeny due to disruptions in pollen diversity and pollinator mobility (Breed et al. 2015). Mating systems also contribute to the structure of genetic diversity (Hamrick and Godt 1996) and while most tropical trees are facultative outcrossers, bi-parental inbreeding can occur in species with limited gene dispersal capabilities (Ellstrand and Elam 1993; Collevatti et al. 2001a; Castilla et al. 2017). Genetic variation, measured in terms of heterozygosity, is often significantly correlated with fitness (Reed and Frankham 2003; Nutt et al. 2016). It is therefore important to assess both contemporary and historic gene flow patterns to identify the strength and spatial scale at which evolutionary forces act upon populations (Stockwell et al. 2003). This will aid management of species in the face of anthropogenic habitat modification and exploitation of forest resources.

Fontainea picrosperma C.T. White (Euphorbiaceae) is a dioecious, subcanopy tree endemic to upland tropical rainforests on the Atherton Tablelands, Queensland, Australia. The species is locally common but has a restricted natural range. The region has been subject to natural habitat fragmentation during the climatic fluctuations of the PlioPleiestocene that led to rainforest species retreating to moist refugia when climate conditions cooled and recolonized surrounding areas once climate conditions improved (Kershaw et al. 2007). Fontainea picrosperma's current discontinuous distribution is due to anthropogenic habitat fragmentation primarily as a result of agricultural expansion, but also due to urban settlements. Fontainea picrosperma is the source of tigilanol tiglate (Boyle et al. 2014; Linkliter et al. 2015), a small molecule, natural product used for the local treatment of solid tumors in humans and companion animals (Linkliter et al. 2015; Miller et al. 2019). Tigilanol tiglate is not synthetically tractable, so production of the drug on a commercial scale relies on raw material harvested from plantations of $F$. picrosperma. It is critical to understand the scale of realized gene flow across generations as well as the overall genetic diversity of the species throughout its natural range to optimize production through selective breeding and genetic improvement of planting stock.

Many studies have examined gene flow and population genetic structure in rainforest canopy species, however understorey species remain underrepresented. This study follows on from the work conducted by Lamont et al. (2016) who studied the population genetics of $F$. picrosperma across the species distribution. Here, we identified localized patterns of gene flow and estimated the population genetic structure between subpopulations of adults and juveniles in natural populations of $F$. picrosperma using microsatellite markers. Specifically, we asked (1) what is the distance of pollen-mediated gene flow and what proportion of seeds are sired by local males? (2) How many males contribute to progeny for each mother tree and how 
Table 1 Sampling method used for each mother tree

\begin{tabular}{lllll}
\hline Mother & Population & Year fruit collected & Number of males sampled & Number of seedlings \\
\hline A156 & Evelyn Highlands 1 & $2014 / 2015$ & 32 & 13 \\
A336 & Evelyn Highlands 1 & $2015 / 2016$ & 31 & 26 \\
B27 & Boonjie & $2015 / 2016$ & 43 & 45 \\
B283 & Boonjie & $2014 / 2015$ & 17 & 19 \\
B595 & Boonjie & $2014 / 2015$ & 34 & 17 \\
B706 & Boonjie & $2014 / 2015$ & 16 & 15 \\
E17 & Topaz & $2014 / 2015$ & 6 & 19 \\
J15 & Evelyn Highlands 2 & $2014 / 2015$ & 40 & 20 \\
J169 & Evelyn Highlands 2 & $2014 / 2015$ & 44 & 20 \\
J424 & Evelyn Highlands 2 & $2014 / 2015$ & 37 & 20 \\
Total & & & 300 & 214 \\
\hline
\end{tabular}

does male reproductive fitness relate to paternal tree characteristics including flowering effort and location (direction and distance) relative to the mother tree? (3) What are the levels of genetic diversity in adult trees and juveniles in the population and what are the levels of genetic differentiation between generations? (4) Are individuals growing near to each other more related than expected from mating two random individuals?

\section{Materials and methods}

\section{Study species and site}

Fontainea picrosperma is a subcanopy tree to $25 \mathrm{~m}$ (Jessup and Guymer 1985) endemic to the complex mesophyll and notophyll vine forests on the Atherton Tablelands, north Queensland, Australia. The species possesses small, white and fragrant flowers that have an unspecialized structure and an open access receptacle that are likely to be pollinated by small generalist insects (Grant et al. 2017). Flowering occurs simultaneously between individuals within subpopulations from September to November. The red drupaceous fruits (up to $3 \mathrm{~cm}$ diameter) ripen in December and January and are dispersed primarily by gravity. Secondary long-distance seed dispersal can occur either by hydrochory along drainage lines or zoochorous vectors (Cooper 2004; Lamont et al. 2016). Natural stands of $F$. picrosperma therefore are not uniformly distributed within appropriate habitat, but rather form small, but dense clumps or clusters (2-10 m inter-tree spacing) with 50:50 male:female ratios (Lamont et al. 2016; Grant et al. 2017). These clumps or clusters are often isolated from neighboring clumps with no conspecific individuals found in between.

Data in this study were collected from trees in discrete populations from across the natural range of the species. The collection locations are labeled according to place names and are described in detail by Lamont et al. (2016).
The populations included in this study were Boonjie, East Barron, Malanda, Topaz, Gadgarra, Towalla, and Evelyn Highlands. We use the term subpopulation when more than one site, representing one clump or cluster, was sampled within a population.

\section{Sample collection}

\section{Pollen-mediated gene flow and male fitness}

We estimated pollen movement by direct paternity analysis using seedling cohorts of selected mother trees from across the $F$. picrosperma geographic range. Mother trees were selected based on the number of fruit that had matured and fallen at the time of sampling as well as their physical location within the discrete clump or cluster. A representative sample of fruit were collected from the base of 10 female trees (mother trees) from four populations (A156; A336; B27; B283; B595; B706; E17; J15; J169; and J424) during the 2014/2015 reproductive season. Very few seedlings survived in the nursery from two female trees and therefore we re-collected from two mother trees (A336 and B27) during the 2015/2016 reproductive season (Table 1). The subpopulations of "Evelyn Highlands 1" and "Evelyn Highlands 2" are from the same refugial population approximately $3.5 \mathrm{~km}$ apart. Locations of all males within a $30 \mathrm{~m}$ radius of each of the mother trees were mapped using a compass and tape measure. This spatial range was selected because it represents the typical approximate scale of the local density estimates of discrete clumps or clusters of $F$. picrosperma. By sampling a $30 \mathrm{~m}$ radius around the mother tree, we estimated that we captured at least $90 \%$ of individuals located within the clump. We sampled to $35 \mathrm{~m}$ around one mother tree, B283, to capture three males tree located just outside the sampling radius. Mother tree E17 was from a small, isolated population, Topaz, where every male individual was sampled and mapped (16 m radius). 
A leaf was sampled from each male and the mother tree for genetic analysis (Table 1). The height, diameter at breast height (dbh) and flowering effort were recorded for each male sampled. Flowering effort was determined by the number of inflorescences per tree and measured on a scale from 1 to 5 $(1 \leq 10 ; 2=10-20 ; 3=20-50 ; 4=50-75 ; 5 \geq 75)$. Trees that were not flowering because they were juveniles were not considered as candidates and were not sampled. 20-60 seeds (according to permit limitations) from each mother tree were sown in the nursery at the University of the Sunshine Coast (USC, Sippy Downs, QLD, Australia), where 13-44 seeds per individual germinated (Table 1). Leaf tissue from each of the germinated seedlings was collected for genetic analysis.

\section{Genetic diversity and differentiation in adult trees and juveniles}

We examined the genetic diversity of $F$. picrosperma and genetic differentiation between age cohorts using 187 adult trees (height $>2.5 \mathrm{~m}$ ) and 122 juveniles (height $\leq 2.5 \mathrm{~m}$ ) from nine $F$. picrosperma populations in the 2012-2013 reproductive season (Table 2). For each sampling site, a focal point was randomly selected, and trees were sampled in an expanding radius circling the focal point. The radius expanded to a maximum of $50 \mathrm{~m}$, more typically $30 \mathrm{~m}$, which captured at least $90 \%$ of all trees within the clump or cluster. Each sampling site represents one subpopulation. The number of samples from each subpopulation were dependent on-site characteristics including the numbers and density of individuals present. Three subpopulations (focal points) were chosen from across the Boonjie population (Table 2) because Boonjie is the largest population of $F$. picrosperma. The subpopulations, "Boonjie 1 and Boonjie 2" are approximately $400 \mathrm{~m}$ apart. "Boonjie 3" is approximately a further $3.5 \mathrm{~km}$ east. The three subpopulations are within continuous rainforest but represent discrete clumps.

Table 2 Number of adult and juvenile $F$. picrosperma individuals sampled from each population

\begin{tabular}{lll}
\hline Population & $A_{i}$ & $J_{i}$ \\
\hline Evelyn Highlands & 24 & 4 \\
Boonjie 1 & 26 & 17 \\
Boonjie 2 & 38 & 27 \\
Boonjie 3 & 17 & 14 \\
Malanda & 12 & 19 \\
Topaz & 13 & 6 \\
Gadgarra & 14 & 16 \\
East Barron & 24 & 6 \\
Towalla & 19 & 13 \\
Total & 163 & 118 \\
\hline
\end{tabular}

$A_{i}$ is the number of adults $(>2.5 \mathrm{~m})$ sampled, $J_{i}$ is the number of juveniles $(\leq 2.5 \mathrm{~m})$ sampled in each population

\section{DNA extraction and microsatellite analysis}

Genomic DNA was extracted from silica-dried leaf tissue using the DNeasy ${ }^{\mathrm{TM}}$ 96-well kit or the DNeasy ${ }^{\mathrm{TM}}$ Plant Mini Kit (Qiagen, Valencia, California, USA, Hilden, Germany) following the manufacturer's instructions. Eleven polymorphic microsatellite loci (between 2 and 7 alleles per locus), previously developed and optimized for $F$. picrosperma (Agostini et al. 2013), were used to genotype all sampled individuals following the method detailed in Lamont et al. (2016). A total of $281 \mathrm{~F}$. picrosperma individuals (adults and juveniles) were genotyped for the genetic diversity and differentiation study using the 11 loci. An additional six microsatellite loci with consistent PCR amplification, clear allelic variation, and clarity of electrophoretic signatures were developed for $F$. picrosperma and used in the paternity analysis (Table S1). These loci were developed to increase the discriminatory exclusion power of the paternity analysis. A total of 524 individuals comprised of mother trees, seedlings and candidate father trees were genotyped for the paternity analysis.

The forward primer of each locus was direct-labeled with a fluorescent dye (VIC, PET, FAM, NED). Two multiplex PCR pools (Pool 1: FP38, FP68, FP84; Pool 2: FP66, FP69, FP82) were amplified using the Multiplex PCR Plus Kit (Qiagen). Forward and reverse primers for each multiplex pool were combined in a $10 \times$ primer mix. Reactions, with volumes adjusted to $10 \mu \mathrm{L}$, each contained $1.25 \mu \mathrm{L}$ of $10 \times$ primer premix, $6.25 \mu \mathrm{L}$ of Qiagen Multiplex Buffer, $3 \mu \mathrm{L}$ of ddH2O, and $2 \mu \mathrm{L}$ of template gDNA. Where samples had to be repeated, single PCR reactions, with volumes adjusted to $10 \mu \mathrm{L}$, each contained $0.3 \mu \mathrm{L}$ forward and $0.3 \mu \mathrm{L}$ reverse primer, $8.425 \mu \mathrm{L}$ of $\mathrm{ddH}_{2} \mathrm{O}, 1.5 \mu \mathrm{L}$ PCR reaction buffer, 1.2 $\mu \mathrm{L}$ dNTP, $1.2 \mu \mathrm{L} \mathrm{MgCl}_{2}, 0.075 \mu \mathrm{L}$ Taq DNA Polymerase and $2.0 \mu \mathrm{L}$ of template gDNA. Amplification for the microsatellite loci was performed using an Eppendorf Mastercycler (Hamburg, Germany) with cycling conditions as follows: initial denaturation at $95^{\circ} \mathrm{C}$ for $3 \mathrm{~min}$, followed by 35 cycles of $94{ }^{\circ} \mathrm{C}$ for $30 \mathrm{~s}, 57^{\circ} \mathrm{C}$ for $30 \mathrm{~s}$, and $72{ }^{\circ} \mathrm{C}$ for $45 \mathrm{~s}$ with a final extension at $72^{\circ} \mathrm{C}$ for $10 \mathrm{~min}$. PCR products were separated by capillary electrophoresis on an AB 3500 Genetic Analyser (Applied Biosystems). Fragment sizes were determined relative to an internal lane standard (GS-600 LIZ; Applied Biosystems) using GENEMARKER v. 2.4.0 (SoftGenetics LLC, PA, USA) and double-checked manually. A subset of samples were run a second time to assure accuracy of genotype reads and minimize the risk of non-amplifying alleles. Individual loci with low intensity or missing peaks were also amplified and genotyped a second time, after which, if they failed to amplify, they were included as missing data. 97.19 and $99.76 \%$ of all loci was successfully amplified and scored for the paternity analysis and for the genetic diversity and differentiation study, respectively. 


\section{Statistical analysis}

\section{Pollen-mediated gene flow and male fitness}

We used CERVUS 3.0.3 (Kalinowski et al. 2007) to perform paternity analysis on seedling cohorts from 10 mother trees using 17 loci. CERVUS uses maximum likelihood for statistical evaluation of progeny-parent pairs (Oddou-Muratorio et al. 2003). Offspring genotypes that conflicted with the assumed mother tree genotypes were excluded before assigning paternal parents. These conflicts arose because seeds were collected from under the canopy of the presumed mother trees and in some instances, the presence of proximate female conspecifics led to field-based misallocation of maternal parents. We ran the program based on the multilocus genotypes of each mother tree and their associated seedlings and the candidate father trees. Simulations on paternity were run using the following parameters: 100,000 simulated offspring, the proportion of mistyped loci was set at 0.01 , and the proportion of candidate fathers sampled was estimated at 0.90 .

Critical Delta values were obtained from simulations and used as a criterion for parentage assignment. We compared trio Delta scores to assign the father with "strict" $(>80 \%)$ and "most likely" $(<80 \%)$ confidence levels. If the seedling received a negative LOD score, no paternal parent was sampled, and the seedling's father was left unassigned. Trio LOD scores were used to determine if there was more than one equally-likely male candidate (equal LOD scores). Two male candidates for each of two seedlings from the mother tree $\mathrm{J} 15$ received an equal LOD score and thus were assigned joint paternity. These fathers were allocated a score of 0.5 each for the sired seedling and allocated the "most likely" confidence level. We manually checked the CERVUS assignments and none of the paternity assignments ("strict" or "most likely") had greater than one mismatch between parent pairs and offspring genotypes (i.e., no greater than one trio mismatches).

Null alleles and allelic drop out are likely to occur in microsatellite studies (Ashley 2010). However, simulation studies have shown that parentage assignment using likelihood-based parentage techniques are robust against Type II errors, i.e., when a true parent is excluded due to mistyping at one or more loci (Oddou-Muratorio et al. 2003). Nevertheless, MICRO-CHECKER v2.2.3 (van Oosterhout et al. 2004) was used to check for scoring errors, homozygote excess, large allele dropout and potential null alleles based on 1000 bootstraps. There was no evidence of homozygote excess, scoring errors, large allele dropout or null alleles.

We calculated the maximum pollen immigration rate as the percent of progeny that could not be assigned a father at any confidence level (negative LOD score). We then calculated the conservative minimum pollen immigration rate as the percent of progeny that could not be assigned a father with "strict" (>80\%) confidence. Fontainea picrosperma is a dioecious species and so the parentage analysis can determine the pollen dispersal distance for each mating event. The spatial position of all candidate fathers was recorded and used to estimate the average distance of pollen dispersal. We compared the frequency distribution of the distances among putative male parents with the frequency distribution of the realized pollination using the Kolmogorov-Smirnov test (K-S test; Sokal and Rohlf 1995) implemented in "R" (R Development Core Team 2013) to determine if mating success was a function of distance between male trees and mother trees.

We assessed the relationship between paternal tree characteristics and male (reproductive) fitness. Individual male fitness was determined by the proportion of seeds sired by a given male on a mother tree. We used both "strict" $(n=135)$ and all CERVUS assignments $(n=176)$ in two separate analyses. Paternal characteristics: height, dbh and flowering effort were significantly autocorrelated (Spearman's Rank correlation; Height $\times$ dbh $r_{\mathrm{s}}(309)=0.747$, $P=0.001$; Height $\times$ Flower count $r_{\mathrm{s}}(309)=0.729, P=$ 0.001 ; dbh $\times$ Flower count $\left.r_{\mathrm{s}}(309)=0.789, P=0.001\right)$. Therefore, we tested for differences in number of seeds sired between categories of flowering effort using a Kruskal-Wallis $H$ test with Bonferroni correction for multiple comparisons. The distances between the mother tree and candidate father trees were grouped into five meter intervals $(0-5 ; 6-10 ; 11-15 ; 16-20 ; 21-25 ; 26-35 \mathrm{~m})$. We then used a Spearman's Rank correlation to determine the relationship between male fitness and distance to the mother. To determine if the movement of pollinators is influenced by prevailing winds the direction of the candidate male to the mother tree was grouped into eight categories (representing $45^{\circ}$ ) and then analysed for each mother tree separately using a Spearman's Rank correlation. All inferential analyses were performed using SPSS (IBM SPSS Inc. Released (2016)).

\section{Genetic diversity and differentiation in adult trees and juveniles}

The original 11 microsatellite loci reported by Lamont et al. (2016) were used in the genetic diversity and differentiation analysis of adult and juvenile subpopulations. GenAlex 6.5 (Peakall and Smouse 2012) was used to calculate the mean number of alleles per locus $\left(N_{\mathrm{A}}\right)$ and expected heterozygosity $\left(H_{\mathrm{E}}\right)$ at Hardy-Weinberg equilibrium for adults and juveniles from nine subpopulations. Allelic richness $\left(A_{\mathrm{R}}\right)$ and private allelic richness $\left(P A_{\mathrm{R}}\right)$ was estimated using HP RARE (Kalinowski 2005) using a minimum sample size of eight. The average pair-wise level of genetic differentiation $\left(F_{\mathrm{ST}}\right)$ was calculated using multilocus comparisons based on 999 permutations to quantify the partitioning of genetic differentiation 
Table 3 Results of the CERVUS analysis of pollen dispersal for the sampled F. picrosperma mother trees, showing the number of offspring that had fathers assigned with "strict" $(>80 \%)$ and "most likely" $(<80 \%)$ confidence levels, and those that were unable to be assigned

\begin{tabular}{|c|c|c|c|c|c|c|}
\hline \multirow[t]{2}{*}{ Mother } & \multirow[t]{2}{*}{$n$} & \multicolumn{3}{|c|}{ Number of seedlings assigned parentage } & \multicolumn{2}{|c|}{ Number of fathers } \\
\hline & & Strict $(\%)$ & Most likely (\%) & Unassigned (\%) & Strict & All assignments \\
\hline A156 & 13 & $6(46.1)$ & $3(23.1)$ & $4(30.8)$ & 5 & 7 \\
\hline A336 & 26 & $19(73.1)$ & $3(11.5)$ & $4(15.4)$ & 13 & 16 \\
\hline B27 & 45 & $34(75.6)$ & 0 & $11(24.4)$ & 18 & 18 \\
\hline B283 & 19 & $13(68.4)$ & 0 & $6(31.6)$ & 7 & 7 \\
\hline B595 & 17 & $15(88.2)$ & 0 & $2(11.8)$ & 10 & 10 \\
\hline B706 & 15 & $15(100)$ & 0 & 0 & 5 & 5 \\
\hline E17 & 19 & $13(68.4)$ & 0 & $6(31.6)$ & 4 & 4 \\
\hline $\mathrm{J} 15$ & 20 & $7(35)$ & $12(60)$ & $1(5)$ & 7 & 16 \\
\hline J169 & 20 & $4(20)$ & $16(80)$ & 0 & 4 & 14 \\
\hline $\mathrm{J} 424$ & 20 & $9(45)$ & $7(35)$ & $4(20)$ & 8 & 14 \\
\hline Total & 214 & $135(63.1)$ & $41(19.2)$ & $38(17.7)$ & 81 & 111 \\
\hline
\end{tabular}

Percentages of each category in relation to the total number of seedlings sampled from each mother tree are shown in parentheses. Number of fathers for assigned seedlings of each $F$. picrosperma mother tree showing the number of male candidates which could be assigned paternity under conditions of "strict" confidence and the total number able to be assigned ("strict" and "most likely")

$n$ is the number of seedlings between adult trees and juveniles in each subpopulation using GenAlex 6.5 (Peakall and Smouse 2012).

Statistical comparisons were carried out in IBM SPSS 24 (IBM SPSS Inc. Released 2016) to determine whether there were significant differences in diversity $\left(H_{\mathrm{E}}, A_{\mathrm{R}}, P A_{\mathrm{R}}\right)$ between the adult trees and juveniles for each subpopulation. All data sets did not meet the assumptions of parametric tests and were subsequently compared using Mann-Whitney $U$-tests.

We calculated mean within group pairwise genetic relatedness $(r)$ for each subpopulation of adults and juveniles sampled using Lynch and Ritland (1999) $\left(l_{x y}\right)$ estimator in GenAlex (Peakall and Smouse 2012). Significant differences in mean relatedness were tested using 9999 permutations and 9999 bootstrap resamplings to calculate the upper and lower $95 \%$ confidence intervals for the expected range of $l_{x y}$ based on the sampled population and within subpopulation estimates of mean relatedness. Subpopulation $l_{x y}$ values that fall above the $95 \%$ expected values from permutations indicate a higher degree of relatedness that expected from random mating across the sampled population.

\section{Results}

\section{Pollen-mediated gene flow and male fitness}

From the sampled population, $135(63.1 \%)$ of the 214 individual seedlings tested could be assigned paternity with "strict" confidence (Table 3). An additional 41 (19.2\%) seedlings were assigned a father when considering the "most likely" CERVUS assignments (Table 3). The males assigned as the "most likely" father had zero (87\%) or one (13\%) loci mismatch. The "most likely" father could not be assigned paternity with "strict" confidence because the second (or more) "most likely" father also had zero or one mismatches and thus the delta score was close to zero. Therefore, we believe that false mismatches have occurred and up to $82.3 \%$ of fathers could be assigned to offspring when accounting for all CERVUS assignments ("strict and most likely"). However, our sampling method of a $30 \mathrm{~m}$ radius surrounding the mother tree can potentially downwardly bias the results of the "most likely" father assignments towards short distance pollen flow. As such, the results of the "most likely" CERVUS assignments must be received with caution.

The total mean pollen immigration rate from greater than $30 \mathrm{~m}$ was $36.9 \%$ (maximum pollen immigration rate; $n=79$; Fig. 1a) when considering fathers that could be assigned with "strict" confidence and $17.7 \%$ (minimum pollen immigration rate; $n=38$ ) when considering all CERVUS assignments (Fig. 1b).

We found that $27 \%(n=81)$ of the 300 candidate fathers sampled, sired seedlings from the 10 mother trees tested (Table 3), when using "strict" CERVUS assignments (cf. $37 \%$ of candidate fathers for "all" CERVUS assignments). Mother tree E17 had one of the lowest number of fathers for the seedling cohort sampled due to the low number of available candidate fathers in the small, isolated population. Most of the assigned fathers sired only a single seed (Fig. 2), and these seeds represented $74.1 \%$ of the total assigned offspring (cf. $74.3 \%$ for "all" CERVUS assignments). In contrast, one or two males sired greater than $10 \%$ of the total progeny for each mother tree (Fig. 2). 


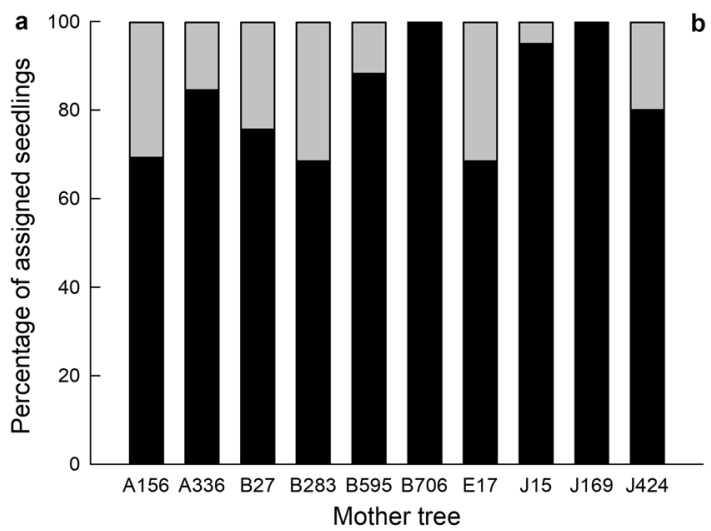

Fig. 1 Percentage of local and immigrant pollinations for each mother tree (number of seedlings per tree: A $156=13 ; \mathrm{A} 336=26 ; \mathrm{B} 27=45$; $\mathrm{B} 283=19 ; \mathrm{B} 595=17 ; \mathrm{B} 706=15 ; \mathrm{E} 17=19 ; \mathrm{J} 15=20 ; \mathrm{J} 169=20 ;$ $\mathrm{J} 424=20$ ). a All assignments ('strict and most likely') are shown in

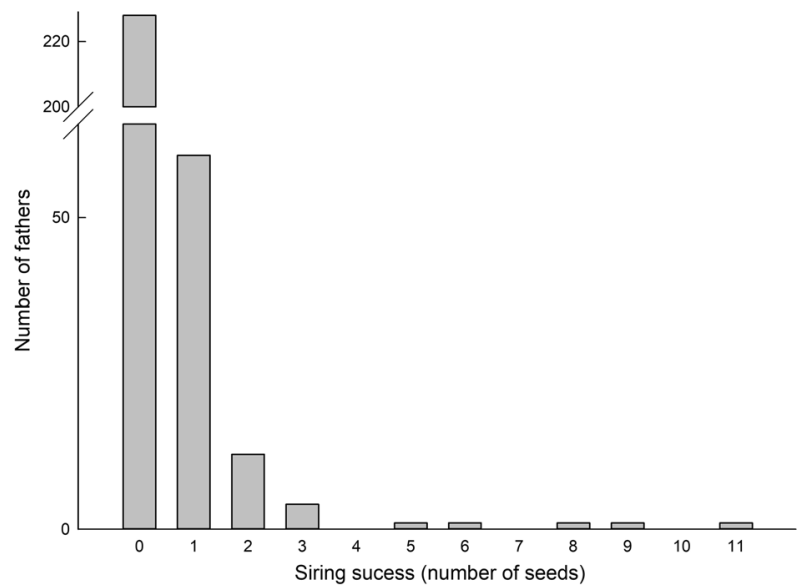

Fig. 2 Total number of candidate fathers vs. number of seedlings assigned with "strict" confidence

Siring success was significantly higher for candidate fathers with more flowers $\left(X^{2}(4)=16.74, P=0.002\right.$, Fig. 3). No significant relationship existed between the direction of the assigned fathers to the mother trees $(P>0.05)$ for all but one mother tree, J424 $\left(r_{\mathrm{s}}(37)=-0.351, P=0.033\right)$, thus wind direction is unlikely to influence the movement of pollinators that results in successful reproduction. The relationship between the number of offspring sired by pollen donors and the distance between the maternal and paternal trees was not significant $\left(r_{\mathrm{s}} \quad(363)=-0.080, \quad P=0.127\right) \quad$ for "strict" assignments. The frequency curve of pollen dispersal was significantly different to the frequency curve of distance measured among all male trees relative to the respective 10 mother trees (Kolmogorov-Smirnov test $(D=0.14743, P=$ $0.03367)$ suggesting a non-random distribution of pollen distances (Fig. 4). The median pollen distance was $15 \mathrm{~m}$ for both "strict" and "all" CERVUS paternity assignments (Fig. 4).

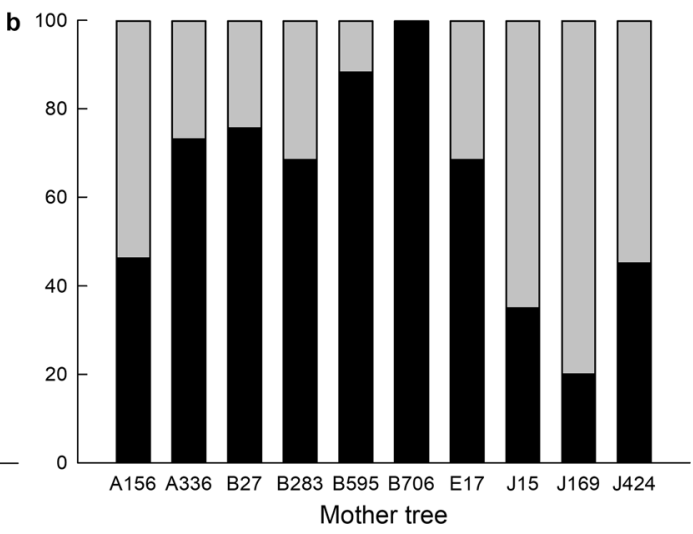

black and unassigned seedlings (minimum pollen immigration rates) are shown in gray. b "Strict" assignments (seedlings assigned with $>80 \%$ confidence) are shown in black and seedlings assigned with $<80$ $\%$ confidence (maximum pollen immigration rates) are shown in grey

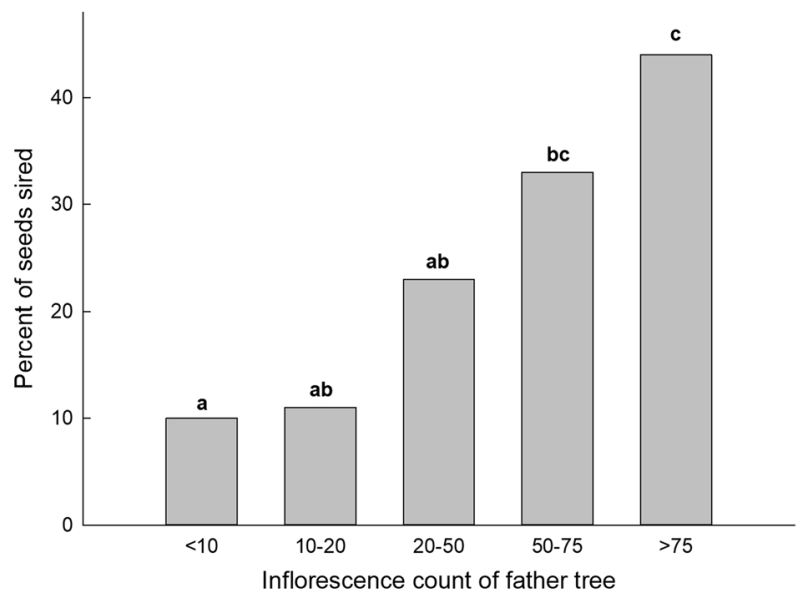

Fig. 3 Percentage of seeds per mother tree sired by fathers relative to male inflorescence number (assigned with "strict" confidence). Categories with different letters are significantly different $(P<0.05$, Kruskal-Wallis $H$-test, Stepwise step-down Bonferroni correction)

\section{Genetic diversity and differentiation in adult trees and juveniles}

Moderately low levels of genetic diversity were detected, with a total of 43 and 41 alleles resolved across the 11 microsatellite loci used in the analysis of the 187 adults and 122 juveniles, respectively. Mean number of alleles per locus per subpopulation was 2.687 for adult trees and 2.384 for juveniles (Table 4). Mean expected heterozygosity $\left(H_{\mathrm{E}}\right)$ for adult trees was 0.405 and 0.379 for juveniles (Table 4).

No significant differences were found in the mean expected heterozygosity $\left(H_{\mathrm{E}}\right)$, allelic richness $\left(A_{\mathrm{R}}\right)$ and private allelic richness $\left(P A_{\mathrm{R}}\right)$ between adult and juvenile subpopulations $(P>0.05)$. Pairwise population $F_{\mathrm{ST}}$ values 


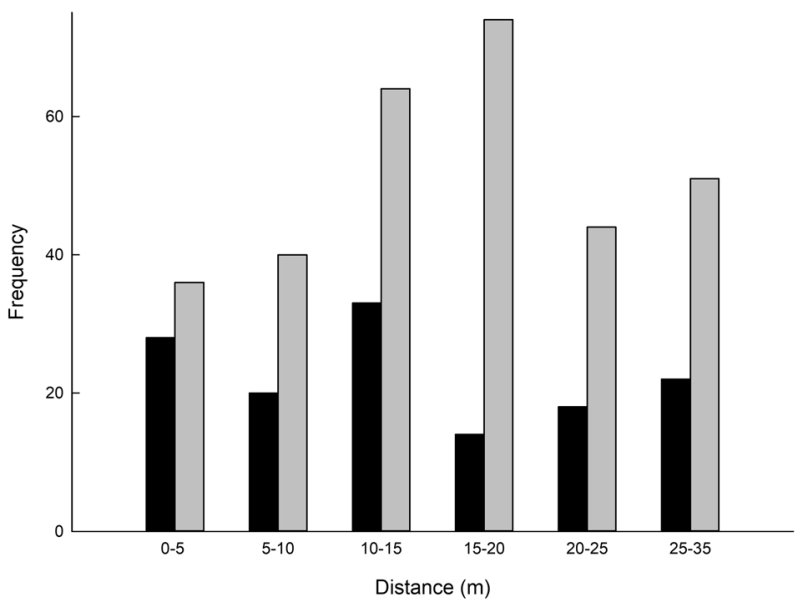

Fig. 4 Frequency distributions of pollen dispersal distances for seeds assigned with "strict" (>80\%) paternity. Black bars represent inter-tree distances between the mother tree and male trees with successful pollination events. Grey bars represent the distance between the mother tree and all candidate male trees that were sampled also displayed negligible genetic differentiation between generations (Table 4).

We found that the mean pairwise relatedness $(r)$ of individuals within adult and juvenile subpopulations were significantly higher $(P>0.05)$ than the simulated confidence intervals for all subpopulations. This indicates that individuals within subpopulations have significantly higher measures of relatedness than expected from mating from two random individuals.

\section{Discussion}

\section{Pollen-mediated gene flow and male fitness}

Our study has detected short distance pollen flow in the subcanopy rainforest tree, $F$. picrosperma. We observed that many males contributed to reproduction and most fathers sired a single seed on the mother tree. Large males with high flowering intensity had a disproportionally higher reproductive success and at least two thirds of successful
Table 4 Comparison of summary genetic measures between 187 adult and 122 juvenile $F$. picrosperma sampled from nine subpopulations

\begin{tabular}{llllllll}
\hline Subpopulation & $n$ & $N_{\mathrm{A}}$ & $H_{\mathrm{E}}$ & $A_{\mathrm{R}}$ & $P A_{\mathrm{R}}$ & $F_{\mathrm{ST}}$ & $r$ \\
\hline Adult subpopulations & & & & & & & \\
Evelyn Highlands 1 & 24 & $2.636(0.31)$ & $0.367(0.06)$ & 2.1 & 0.05 & 0.023 & 0.179 \\
Boonjie 1 & 29 & $3.182(0.35)$ & $0.517(0.04)$ & 2.52 & 0.03 & 0.018 & 0.042 \\
Boonjie 2 & 38 & $3.000(0.27)$ & $0.476(0.03)$ & 2.29 & 0.1 & 0.015 & 0.059 \\
Boonjie 3 & 17 & $2.727(0.20)$ & $0.424(0.04)$ & 2.2 & 0.01 & 0.025 & 0.140 \\
East Baron & 24 & $2.818(0.35)$ & $0.405(0.06)$ & 2.14 & 0.09 & 0.001 & 0.155 \\
Malanda & 12 & $2.545(0.28)$ & $0.448(0.05)$ & 2.26 & 0 & 0 & 0.120 \\
Topaz & 13 & $2.818(0.38)$ & $0.373(0.05)$ & 2.2 & 0.02 & 0.011 & 0.159 \\
Gadgarra & 14 & $2.091(0.21)$ & $0.257(0.06)$ & 1.73 & 0 & 0.003 & 0.285 \\
Towalla & 19 & $2.364(0.28)$ & $0.377(0.05)$ & 2.03 & 0 & 0 & 0.133 \\
Mean & & $2.687(0.11)$ & $0.405(0.02)$ & 2.16 & 0.03 & 0.011 & - \\
Juvenile subpopulations & & & & & & & \\
Evelyn Highlands 1 & 4 & $1.818(0.24)$ & $0.307(0.08)$ & 1.82 & 0 & - & 0.224 \\
Boonjie 1 & 17 & $2.545(0.21)$ & $0.447(0.03)$ & 2.15 & 0.03 & - & 0.160 \\
Boonjie 2 & 27 & $2.909(0.25)$ & $0.453(0.04)$ & 2.26 & 0.04 & - & 0.061 \\
Boonjie 3 & 14 & $2.545(0.21)$ & $0.386(0.05)$ & 2.09 & 0 & - & 0.119 \\
East Baron & 6 & $2.000(0.19)$ & $0.340(0.06)$ & 1.91 & 0 & - & 0.189 \\
Malanda & 19 & $2.545(0.25)$ & $0.436(0.06)$ & 2.23 & 0.01 & - & 0.092 \\
Topaz & 6 & $2.455(0.34)$ & $0.360(0.07)$ & 2.17 & 0.05 & - & 0.164 \\
Gadgarra & 16 & $2.364(0.24)$ & $0.326(0.06)$ & 1.9 & 0.02 & - & 0.211 \\
Towalla & 13 & $2.273(0.19)$ & $0.359(0.06)$ & 1.96 & 0 & - & 0.166 \\
Mean & & $2.384(0.11)$ & $0.379(0.02)$ & 2.05 & 0.02 & - & - \\
\hline Mean ssapopu
\end{tabular}

Mean subpopulation values averaged across the 11 loci are shown with standard errors in parentheses where calculated

$n$ is the number of individual plants; $N_{\mathrm{A}}$ is the mean number of alleles per locus, $H_{\mathrm{E}}$ is the expected heterozygosity, $A_{\mathrm{R}}$ is the allelic richness, $P A_{\mathrm{R}}$ is the private allelic richness, $F_{\mathrm{ST}}$ is the genetic differentiation among populations, $r$ is the average pairwise relatedness within subpopulations 
mating events occurred with male trees located within a $30 \mathrm{~m}$ radius of the mother tree.

Our findings demonstrate that pollen dispersal in $F$. picrosperma in the subcanopy occurs over short distances compared to many insect-pollinated canopy trees (Akihiro et al. 2000; Kenta et al. 2004; Ward et al. 2005; Hardesty et al. 2006; Born et al. 2008; Monthe et al. 2017). The long dispersal distances reported for canopy species are partly because these taxa generally occur at low population densities. If only distant trees are flowering, pollinators must travel long distances to locate resources. While the breakdown of nearest-neighbor mating can occur (Dick et al. 2008), pollen dispersal patterns of many insect-pollinated tropical trees are influenced by preferential visitations to close neighboring trees (Silva et al. 2011; Theim et al. 2014; Noreen et al. 2016). The short distance pollen dispersal we observed for $F$. picrosperma can be partly attributed to the species clumped distribution and synchronous flowering. Pollinators are preferentially visiting trees within the clump of $F$. picrosperma such that on average, two-thirds of the successful reproductive events occurred within a $30 \mathrm{~m}$ radius of the mother tree. Other studies of rainforest understorey and subcanopy species have also found a high proportion of short distance pollination events, for example, in Piper shrub spp. that have high density, aggregated populations (Lasso et al. 2011), and Rhododendron simsii, that have highly synchronous flowering events (Hahn et al. 2017). Many males contributed to successful reproduction of individual $F$. picrosperma females with approximately $75 \%$ of the assigned fathers siring a single seed. Together, these findings conform to the theory of density-dependent animal pollination, which assumes that tree species occurring at low densities receive pollen from fewer individuals than trees in denser populations, where dispersal distances are lower (Murawski and Hamrick 1991; Bianchi and Cunningham 2012; Castilla et al. 2017).

Spatial considerations as well as the attractiveness of floral displays of individual trees are important factors in determining pollinator-assisted gene flow (Barrett and Harder 1996; Degen and Roubik 2004; Duminil et al. 2016). Our results show that while many male trees sired seeds, the contributions to reproduction were uneven. Consistently, only one or two males were responsible for a proportionally greater number of successful fertilization events across all 10 mother trees. As expected, large males displaying high intensity flowering had significantly greater reproductive success than males with less flowers. Flower count was autocorrelated with tree stem diameter size (dbh) in our study, this finding is congruent with other studies of tropical trees where dbh size class was positively correlated with mean individual fecundity (Latouche-Hallé et al. 2004; Naoki et al. 2012; Monthe et al. 2017). Greater biomass has been found to result in greater male fitness in many plant species (Younginger et al. 2017), and may help to explain the skewed number of fathers found to be siring progeny in F. picrosperma.

In addition, plant-pollinator relationships can influence pollen dispersal distances. The floral structure of $F$. picrosperma suggests that it is likely to be pollinated by small generalist insects (Grant et al. 2017). The predominant floral visitors in Australian tropical forests are small insects, particularly beetles, flies, small bees, and thrips (Irvine and Armstrong 1991; Gross 2005). This class of generalist pollinators are known to visit unspecialized flowers and often move shorter distances compared to specialized insects, larger insects, or vertebrates (Dick et al. 2008). The $18-37 \%$ pollen immigration rate suggests that some pollinator's of $F$. picrosperma are able to transport pollen greater than $30 \mathrm{~m}$. However, it remains unclear how far pollen can travel beyond this radius. We used direction to the mother tree as a proxy for prevailing wind conditions and did not find any significant correlation between mother trees and the direction of the pollen donors within the sampled plot area. This is presumably because of the lack of wind and/or turbulent wind patterns under the dense rainforest canopy. Gene flow in $F$. picrosperma is also limited by the transport of pollen by pollinators (Grant et al. 2017), which further reduces opportunities for long-distance pollen flow.

While the mean pollen dispersal distance herein is potentially underestimated due to our sampling method that aligned with the approximate clump size, we could confidently assign $63 \%$ of successful pollen donors from within the plot. Distance between the mother tree and the pollen source was not significantly correlated. This statistic is somewhat confounded by the fine $(\sim 30 \mathrm{~m})$ scale of this study and given the localized pollination rate, distance, when analysed over a larger scale, is likely to be an important factor in reproductive success. Particularly given that $F$. picrosperma is dioecious and pollen-mediated gene flow is not restricted by self-pollination. Our results implying predominantly short distance pollen dispersal suggests that cultivation of the fruit will require a significant number of males within the carefully designed plantation to increase efficient pollination.

We believe the maximum pollen immigration rate $(37 \%$ greater than $30 \mathrm{~m}$ ) observed in this study is conservative due to the low genetic diversity of $F$. picrosperma and subsequently low discriminatory power of the microsatellite markers used in this study. False negatives are likely to have occurred as a great majority ( $87 \%$ ) of the males assigned the "most likely" father had zero loci mismatches with the offspring when accounting for the mother's genotype. Thus, localized pollination events could be up to $82 \%$ when accounting for all paternity assignments. However, it is important to highlight that the fine scale of our study has the 
potential to downwardly bias the calculated dispersal range estimates when accounting for fathers assigned as "most likely". Moreover, our results are reflective of a single reproductive year and we acknowledge that pollinator composition can change over space and time (Dick et al. 2008; Kenta et al. 2004) and that natural flower and seed production can be influenced by natural climatic variations between years, all of which can produce different patterns of gene flow.

\section{Genetic diversity and differentiation in adult trees and juveniles}

The genetic diversity measures reported in this study are congruent with similar populations of $F$. picrosperma reported by Lamont et al. (2016) and for the related species $F$. rostrata (Conroy et al. 2019). Summary measures of genetic diversity were almost identical for both $F$. picrosperma adult and juvenile cohorts $\left(H_{\mathrm{E}}, A_{\mathrm{R}}, P A_{\mathrm{R}} ; P>0.05\right)$. Measures of diversity such as overall allelic richness (2.16 in adult trees and in 2.05 juveniles) and expected hetrozygosity $\left(H_{\mathrm{E}}\right)$ ( 0.405 for adult trees and 0.379 for juveniles) are relatively low when compared to microsatellite-based studies on tropical rainforest tree species reported elsewhere. For example, reports of $H_{\mathrm{E}}$ in outcrossing rainforest taxa range between 0.732 and 0.907 (Collevatti et al. 2001b; Naito et al. 2005; Carneiro et al. 2009; Sebbenn et al. 2011; Melo and Franceschinelli 2016; Monthe et al. 2017) while self-compatible species $\left(H_{\mathrm{E}}=0.629-0.797\right.$; Latouche-Hallé et al. 2004; Tani et al. 2009), and species surviving in highly fragmented populations $\left(H_{\mathrm{E}}=0.662-0.701\right.$; Gaino et al. 2010; Wang et al. 2014) are still considerably higher than $F$. picrosperma. From the limited studies available, the genetic diversity of $F$. picrosperma is more akin to other Australian rainforest tree species including Elaeocarpus angustifolius $\left(H_{\mathrm{E}}=0.61\right)$ and E. largiflorens $\left(H_{\mathrm{E}}=0.54\right.$; Rossetto et al. 2007) and species with reported low genetic diversity due to mechanisms such as asexual reproduction (Rossetto et al. 2004; Rossetto and Kooyman 2005; Thurlby et al. 2012).

Genetic variation is often significantly related to population fitness and hence, the evolutionary potential of a species (Reed and Frankham 2003). Yet F. picrosperma has successfully persisted through historical environmental changes with low genetic diversity (Lamont et al. 2016). Euphorbiaceae is a family that exemplifies the postCretaceous diversification of the Australian rainforest flora and Fontainea first appears in the fossil record in the early Tertiary period (Williams and Adam 2010). Expansion and contraction of $F$. picrosperma populations during the climatic oscillations of the Pleistocene over the last 230,000 years (Kershaw et al. 2007) has likely reduced the level of genetic variation within the species, as found in this study and by Lamont et al. (2016), compared to other plant species in biomes with more diverse topography and greater elevation range (Broadhurst et al. 2017). These processes have led to low genetic diversity in other upland taxa in the Australian tropics, such as Elaeocarpus spp. (Rossetto et al. 2009). Species with natural restricted geographical range are also usually less genetically diverse than more widespread species (Arguilar et al. 2008). Habitat fragmentation and degradation that has occurred in the region since European settlement could also have contributed to a loss of genetic diversity due to a reduced number of local and immigrant pollen sources in some populations (Sork and Smouse 2006).

Spatially limited pollen and seed gene dispersal is known to increase the likelihood of similar genotypes mating with each other (Seidler and Plotkin 2006; Ellstrand 2014). We found evidence that individuals were significantly more related than is expected between two random individuals within the adult and juvenile subpopulations studied. These results are concordant with the predominantly short distance pollen flow indicated from our paternity analysis. Theoretically, selfing and mating between close relatives will increase differentiation among populations $\left(F_{\mathrm{ST}}\right)$ by increasing inbreeding (Duminil et al. 2009) and reducing genetic variation at the population level (Loveless and Hamrick 1984). However, we found a lack of genetic differentiation between $F$. picrosperma adults and juveniles (represented by a low $F_{\mathrm{ST}}$ value), despite the adult cohort representing a larger sample of the total available genetic diversity due to a greater number of overlapping generations present than in the juvenile group. The $18-37 \%$ pollen immigration rate (greater than $30 \mathrm{~m}$ ) estimated by paternity assignments could contribute to the lack of differentiation between age cohorts. Only low levels of gene flow are necessary to counteract opposing mutation, drift and selection (Ellstrand 2014). Immigrant pollen can connect populations through gene flow and some empirical evidence has suggested that long distance pollination events attenuate genetic decline due to drift and inbreeding in isolated populations (Ashley 2010). While we do not know how far pollen can travel, Lamont et al. (2016) found recent bottlenecks with subsequent founder effects in two isolated populations of $F$. picrosperma, Malanda (centrally located) and Gadgarra (North-East). This implies that pollen may not travel long distances from the refugial populations of Boonjie and Evelyn Highlands, which are located in the east and west peripheries of the species natural distribution (Lamont et al. 2016).

The lack of genetic differentiation between adult and juvenile groups observed in this study remains consistent with Lamont et al. (2016) who found negligible levels of inbreeding within adult populations of $F$. picrosperma, which is expected in a dioecious species. Deleterious alleles may be purged through an increase in mortality in inbred 
individuals and survivorship of those composed of half or unrelated siblings (Hufford et al. 2003; Naito et al. 2005; Tambarussi et al. 2017). This is a common pattern in longlived species (Duminil et al. 2009). In addition, the large number of males contributing to reproduction of a single seed found in this study suggests that heterogenic pollen pools are received on flowering females. This can maintain variability, reduce the occurrence of full sibling progeny arrays and dilute the effects of kin mating (Breed et al. 2012b). This result may reflect the synchronous flowering and high density of available fathers surrounding the mother tree. However, not all candidate fathers sired offspring. We acknowledge that inbreeding depression can affect initial seed set as well as plant growth (references within Angeloni et al. 2011), which was not studied here.

More than half of the mating events in $F$. picrosperma occur over very limited spatial scales. Population genetic theory suggests that restricted gene flow among populations results in population differentiation and allows populations to evolve independently in response to genetic drift or local natural selection (Slatkin 1987; Ellstrand 1992), which has been demonstrated empirically in some tropical understorey species (Lasso et al. 2011; Theim et al. 2014). In comparison, low genetic differentiation among tropical tree populations has been interpreted as evidence of continuous longdistance, historical gene flow (Dick et al. 2008). Fontainea picrosperma is a species with low interpopulation $F_{\mathrm{ST}}$ (Lamont et al. 2016), however, in the context of low genetic diversity, the short distance pollen dispersal is likely to have contributed to the significant, albeit weak population structuring across $F$. pirosperma's natural distribution. The observed low levels of genetic differentiation and genetic diversity between adult and juvenile cohorts, and the determination that proximate plants are significantly related to each other suggests that this species is highly adapted to its environment, short distance pollen flow does not affect the species capacity to persist in the environment, and there is sufficient long-distance gene flow to keep the level of genetic diversity stable across the species distribution. Future cultivation of the species however, may benefit from mixing genetically dissimilar stocks from across $F$. picrosperma's natural distribution as a means of increasing allelic diversity.

\section{Conclusion}

Our results reveal spatially limited gene dispersal in the subcanopy species, F. picrosperma. Size and flowering effort are more important than distance in determining male fitness at the fine-scale focus in this study. The species' short-distance gene dispersal and skewed success rate of pollen donors is potentially a prelude to genetic impoverishment. However, adult and juvenile subpopulations have similar multilocus genotypes and there is no evidence of an intergenerational loss of diversity. Furthermore, $F$. picrosperma has survived several significant climatic oscillations through the Pleistocene, likely by persisting in refugia offering a more stable environment and it is likely that the low genetic diversity observed in $F$. picrosperma is an indication of its significant adaption to local environmental conditions. Fontainea picrosperma is geographically confined to a region that has been subjected to intense anthropogenic habitat fragmentation since European settlement. It may be that the species' natural clumped distribution coupled with predominantly short distance pollen dispersal helps to attenuate population genetic pressures due to habitat fragmentation. Despite the species' ongoing resilience, low overall genetic diversity may compromise $F$. picrosperma's ability to adapt to changing environmental conditions and extreme stochastic events. Therefore, it is important to conserve the remaining populations of $F$. picrosperma to ensure that the current level of genetic diversity is maintained for both conservation and domestication of this commercially significant species.

\section{Data archiving}

Data have been deposited at Dryad: https://doi.org/10.5061/ dryad.73pn293.

Acknowledgements We thank Tracey McMahon, Anastasia George and Ton Stewart for assistance with sample collection and analysis.

\section{Compliance with ethical standards}

Conflict of interest EcoBiotics Ltd partly funded this research. S.M.O. is a director and shareholder of QBiotics Group Ltd. P.W.R. is a director, employee and shareholder of EcoBiotics Ltd and QBiotics Group Ltd. The remaining authors declare that they have no conflict of interest.

Publisher's note: Springer Nature remains neutral with regard to jurisdictional claims in published maps and institutional affiliations.

\section{References}

Agostini C, Albaladejo RG, Aparicio A, Arthofer W, Berrebi P, Boag PT (2013) Permanent genetic resources added to molecular ecology resources database 1 February 2013-31 March 2013. Mol Ecol Resour 13:760-762

Aguilar R, Quesada M, Ashworth L, Herrerias-Diego Y, Lobo J (2008) Genetic consequences of habitat fragmentation in plant populations: susceptible signals in plant traits and methodological approaches. Mol Ecol 17:5177-5188

Akihiro K, Yoshihiko T, Ting LC, Leong LS, Toshinori O (2000) Estimation of gene flow in the tropical-rainforest tree Neobalanocarpus heimii (Dipterocarpaceae), inferred from paternity analysis. Mol Ecol 9:1843-1852 
Angeloni F, Ouborg NJ, Leimu R (2011) Meta-analysis on the association of population size and life history with inbreeding depression in plants. Biol Conserv 144:35-43

Ashley MV (2010) Plant parentage, pollination, and dispersal: how DNA microsatellites have altered the landscape. Crit Rev Plant Sci 29:148-161

Barrett SCH, Harder LD (1996) Ecology and evolution of plant mating. Trends Ecol Evol 11:73-79

Bawa KS (1992) Mating systems, genetic differentiation and speciation in tropical rain forest plants. Biotropica 24:250-255

Bianchi FJJA, Cunningham SA (2012) Unravelling the role of mate density and sex ratio in competition for pollen. Oikos 121:219-227

Born C, Hardy OJ, Chevallier MH, Ossari S, Attéké C, Wickings JE et al. (2008) Small-scale spatial genetic structure in the central african rainforest tree species Aucoumea klaineana: a stepwise approach to infer the impact of limited gene dispersal, population history and habitat fragmentation. Mol Ecol 17:2041-2050

Boyle GM, D’Souza MMA, Pierce CJ, Adams RA, Cantor AS (2014) Intra-lesional injection of the novel pkc activator EBC-46 rapidly ablates tumors in mouse models. PLoS ONE 9:e108887

Bradshaw CJ, Sodhi NS, Brook BW (2009) Tropical turmoil: a biodiversity tragedy in progress. Front Ecol Environ 7:79-87

Breed MF, Gardner MG, Ottewell KM, Navarro CM, Lowe AJ (2012a) Shifts in reproductive assurance strategies and inbreeding costs associated with habitat fragmentation in central American mahogany. Ecol Lett 15:444-452

Breed MF, Marklund MHK, Ottewell KM, Gardner MG, Harris J, Berton $\mathrm{C}$ et al. (2012b) Pollen diversity matters: revealing the neglected effect of pollen diversity on fitness in fragmented landscapes. Mol Ecol 21:5955-5968

Breed MF, Ottwell KM, Gardner MG, Marklund MHK, Dormontt EE, Lowe AJ (2015) Mating patterns and pollinator mobility are critical traits in forest fragmentation genetics. Heredity 115:108-114

Broadhurst L, Breed M, Lowe A, Bragg J, Catullo R, Coates D et al. (2017) Genetic diversity and structure of the Australian flora. Divers Distrib 23:41-52

Burczyk J, DiFazio SP, Adams WT (2004) Gene flow in forest trees: how far do genes really travel? For Genet 11:179-192

Carneiro FdS, Degen B, Kanashiro M, de Lacerda AEB, Sebbenn AM (2009) High levels of pollen dispersal detected through paternity analysis from a continuous Symphonia globulifera population in the Brazilian Amazon. Ecol Manage 258:1260-1266

Castilla AR, Pope N, Jha S (2016) Positive density-dependent reproduction regulated by local kinship and size in an understorey tropical tree. Ann Bot 117:319-329

Castilla AR, Pope NS, O'Connell M, Rodriguez MF, Treviño L, Santos A et al. (2017) Adding landscape genetics and individual traits to the ecosystem function paradigm reveals the importance of species functional breadth. Proc Natl Acad Sci USA 114:12761-12766

Collevatti RG, Grattapaglia D, Hay JD (2001a) High resolution microsatellite based analysis of the mating system allows the detection of significant biparental inbreeding in Caryocar brasiliense, an endangered tropical tree species. Heredity (Edinb) 86:60-67

Collevatti RG, Grattapaglia D, Hay JD (2001b) Population genetic structure of the endangered tropical tree species Caryocar brasiliense, based on variability at microsatellite loci. Mol Ecol 10:349-356

Conroy GC, Shimizu-Kimura Y, Lamont RW, Ogbourne SM (2019) A multidisciplinary approach to inform assisted migration of the restricted rainforest tree, Fontainea rostrata. PLoS ONE 14:1-21

Cooper WT (2004) Fruits of the Australian tropical rainforest. Nokomis, Melbourne

Degen B, Roubik DW (2004) Effects of animal pollination on pollen dispersal, selfing, and effective population size of tropical trees: a simulation study. Biotropica 36:165-179
Degen B, Sebbenn AM (2016) Genetics and tropical forests. In: Pancel L, Köhl M (eds) Tropical forestry handbook. Springer, Berlin, Heidelberg. pp 885-920.

Dick C, Hardy O, Jones FA, Petit R (2008) Spatial scales of pollen and seed-mediated gene flow in tropical rain forest trees. Trop Plant Biol 1:20-33

Duminil J, Daïnou K, Kaviriri DK, Gillet P, Loo J, Doucet JL et al. (2016) Relationships between population density, fine-scale genetic structure, mating system and pollen dispersal in a timber tree from African rainforests. Heredity 116:295-303

Duminil J, Hardy OJ, Petit RJ (2009) Plant traits correlated with generation time directly affect inbreeding depression and mating system and indirectly genetic structure. BMC Evol Biol 9:177

Eckert CG, Kalisz S, Geber MA, Sargent R, Elle E, Cheptou P-O et al. (2010) Plant mating systems in a changing world. Trends Ecol Evol 25:35-43

Ellstrand NC (1992) Gene flow by pollen: implications for plant conservation genetics. Oikos 63:77-86

Ellstrand NC (2014) Is gene flow the most important evolutionary force in plants? Am J Bot 101:737-753

Ellstrand NC, Elam DR (1993) Population genetic consequences of small population size: implications for plant conservation. Annu Rev Ecol Syst 24:217-242

Gaino APSC, Silva AM, Moraes MA, Alves PF, Moraes MLT, Freitas MLM et al. (2010) Understanding the effects of isolation on seed and pollen flow, spatial genetic structure and effective population size of the dioecious tropical tree species Myracrodruon urundeuva. Conserv Genet 11:1631-1643

Ghazoul J (2005) Pollen and seed dispersal among dispersed plants. Biol Rev Camb Philos Soc 80:413-443

Grant EL, Wallace HM, Trueman SJ, Reddell PW, Ogbourne SM (2017) Floral and reproductive biology of the medicinally significant rainforest tree, Fontainea picrosperma (Euphorbiaceae). Ind Crops Prod 108:416-422

Gross CL (2005) A comparison of the sexual systems in the trees from the Australian tropics with other tropical biomes: more monoecy but why? Am J Bot 92:907-919

Hahn CZ, Michalski SG, Durka W (2017) Gene flow in, and mating system of, Rhododendron simsii in a nature reserve in subtropical China. Nord J Bot 35:1-7

Hamrick JL (2004) Response of forest trees to global environmental changes. Ecol Manage 197:323-335

Hamrick JL, Godt MJW (1996) Effects of life history traits on genetic diversity in plant species. Philos Trans R Soc B 351:1291-1298

Hardesty BD, Hubbell SP, Bermingham E (2006) Genetic evidence of frequent long-distance recruitment in a vertebrate-dispersed tree. Ecol Lett 9:516-525

Hardy OJ, Maggia L, Bandou E, Breyne P, Caron H, Chevallier MH et al. (2006) Fine-scale genetic structure and gene dispersal inferences in 10 Neotropical tree species. Mol Ecol 15:559-571

Hoebee SE, Arnold U, Düggelin C, Gugerli F, Brodbeck S, Rotach P et al. (2007) Mating patterns and contemporary gene flow by pollen in a large continuous and a small isolated population of the scattered forest tree Sorbus torminalis. Heredity 99:47-55

House SM (1992) Population density and fruit set in three dioecious tree species in Australian tropical rainforest. J Ecol 80:57-69

House SM (1993) Pollination success in a population of dioecious rain forest trees. Oecologia 96:555-561

Hufford KM, Hamrick JL, Ashley M (2003) Viability selection at three early life stages of the tropical tree, Platypodium elegans (Fabaceae, Papilionoideae). Evolution 57:518-526

IBM SPSS Inc. Released (2016) SPSS Statistics for Windows, Version24.0. SPSS Inc, Chicago

Irvine AK, Armstrong JE (1991). Beetle pollination in tropical forests of Australia. In: Bawa KS, Hadley M (eds) Reproductive ecology of tropical forest plants. CRC Press, Boca Raton pp 135-149 
Jessup LW, Guymer GP (1985) A revision of Fontainea Heckel (Euporbiaceae - Cluytieae). Austrobaileya 2:112-125

Kalinowski ST (2005) HP-RARE 1.0: a computer program for performing rarefaction on measures of allelic richness. Mol Ecol Notes 5:187-189

Kalinowski ST, Taper ML, Marshall TC (2007) Revising how the computer program CERVUS accommodates genotyping error increases success in paternity assignment. Mol Ecol 16:1099-1106

Kenta T, Isagi Y, Nakagawa M, Yamashita M, Nakashizuka T (2004) Variation in pollen dispersal between years with different pollination conditions in a tropical emergent tree. Mol Ecol 13:3575-3584

Kershaw AP, Bretherton SC, van der Kaars S (2007) A complete pollen record of the last $230 \mathrm{ka}$ from Lynch's crater, north-eastern Australia. Palaeogeogr Palaeoclim Palaeoecol 251:23-45

Lamont RW, Conroy GC, Reddell P, Ogbourne SM (2016) Population genetic analysis of a medicinally significant Australian rainforest tree, Fontainea picrosperma C.T. White (Euphorbiaceae): biogeographic patterns and implications for species domestication and plantation establishment. BMC Plant Biol 16:1-12

Lasso E, Dalling JW, Bermingham E (2011) Strong spatial genetic structure in five tropical Piper species: should the Baker-Fedorov hypothesis be revived for tropical shrubs? Ecol Evol 1:502-516

Latouche-Hallé C, Ramboer A, Bandou E, Caron H, Kremer A (2004) Long-distance pollen flow and tolerance to selfing in a Neotropical tree species. Mol Ecol 13:1055-1064

Levin DA, Kerster HW (1974). Gene flow in seed plants. In: Dobzhansky T, Hecht MK, Steere WC (eds) Evolutionary biology. Springer, Boston, MA. pp 139-220

Linkliter JD, Panizza B, Karapetis CS, Gordon VA, Reddell PW, Lingard KT et al. (2015) Phase 1 dose-escalation study of EBC46 given by intratumoral injection to patients with refractory cutaneous and subcutaneous tumors. In Phase 1 dose-escalation study of EBC-46 given by intratumoral injection to patients with refractory cutaneous and subcutaneous tumors, 2015 ASCO Annual Meeting

Loveless MD, Hamrick JL (1984) Ecological determinants of genetic structure in plant populations. Ann Rev Ecol Syst 15:65-95

Lowe AJ, Boshier D, Ward M, Bacles CFE, Navarro C (2005) Genetic resource impacts of habitat loss and degradation; reconciling empirical evidence and predicted theory for Neotropical trees. Heredity 95:255-273

Lowe AJ, Cavers S, Boshier D, Breed MF, Hollingsworth PM (2015) The resilience of forest fragmentation genetics-no longer a paradox-we were just looking in the wrong place. Heredity 115:97-99

Lynch M, Ritland K (1999) Estimation of pairwise relatedness with molecular markers. Genetics 152:1753-1766

Melo ATdO, Franceschinelli EV (2016) Gene flow and fine-scale spatial genetic structure in Cabralea canjerana (Meliaceae), a common tree species from the Brazilian Atlantic forest. J Trop Ecol 32:135-145

Miller J, Campbell J, Blum A, Reddell P, Gordon V, Schmidt P, Lowden S (2019) Dose characterization of the investigational anticancer drug tigilanol tiglate (EBC-46) in the local treatment of canine mast cell tumours. Front Vet Sci 6:106. https://doi.org/10. 3389/fvets.2019.00106

Monthe FK, Hardy OJ, Doucet JL, Loo J, Duminil J (2017) Extensive seed and pollen dispersal and assortative mating in the rain forest tree Entandrophragma cylindricum (Meliaceae) inferred from indirect and direct analyses. Mol Ecol 26:5279-5291

Murawski DA, Hamrick JL (1991) The effect of the density of flowering individuals on the mating systems of nine tropical tree species. Heredity 67:167-174
Naito Y, Konuma A, Iwata H, Suyama Y, Seiwa K, Okuda T et al. (2005) Selfing and inbreeding depression in seeds and seedlings of Neobalanocarpus heimii (Dipterocarpaceae). J Plant Res 118:423-430

Naoki T, Yoshihiko T, Keita F, Tomoyuki K, Yuriko T, Lee LS et al. (2012) Male fecundity and pollen dispersal in hill Dipterocarps: significance of mass synchronized flowering and implications for conservation. J Ecol 100:405-415

Noreen AME, Niissalo MA, Lum SKY, Webb EL (2016) Persistence of long-distance, insect-mediated pollen movement for a tropical canopy tree species in remnant forest patches in an urban landscape. Heredity 117:472-480

Nutt KS, Burslem DFRP, Maycock CR, Ghazoul J, Khoo E, Hastie AYL et al. (2016) Genetic diversity affects seedling survival but not growth or seed germination in the Bornean endemic Dipterocarp, Parashorea tomentella. Plant Ecol Divers 9:471-481

O'Connell MC, Castilla AR, Lee LX, Jha S (2018) Bee movement across heterogeneous tropical forests: multi-paternal analyses reveal the importance of neighborhood composition for pollen dispersal. Biotropica 50:908-918

Oddou-Muratorio S, Houot M-L, Demesure-Musch B, Austerlitz F (2003) Pollen flow in the wildservice tree, Sorbus torminalis (1.) Crantz. I. Evaluating the paternity analysis procedure in continuous populations. Mol Ecol 12:3427-3439

Ollerton J, Winfree R, Tarrant S (2011) How many flowering plants are pollinated by animals? Oikos 120:321-326

van Oosterhout C, Hutchinson W, Wills DPM, Shipley P (2004) MICRO-CHECKER: software for identifying and correcting genotyping errors in microsatellite data. Mol Ecol Res 4:535-538

Ottewell K, Grey E, Castillo F, Karubian J (2012) The pollen dispersal kernel and mating system of an insect-pollinated tropical palm, Oenocarpus bataua. Heredity 109:332-339

Peakall R, Smouse PE (2012) GenAlEx 6.5: genetic analysis in Excel. Population genetic software for teaching and research update. Bioinformatics 28:2537-2539

R Development Core Team (2013) R: A language and environment for statistical computing. R Foundation for Statistical Computing, Vienna, Austria

Reed DH, Frankham R (2003) Correlation between fitness and genetic diversity. Conserv Biol 17:230-237

Rosetto M, Crayn D, Ford A, Mellick R, Sommerville K (2009) The influence of environment and life-history traits on the distribution of genes and individuals: a comparative study of 11 rainforest trees. Mol Ecol 18:1422-1438

Rossetto M, Crayn D, Ford A, Ridgeway P, Rymer P (2007) The comparative study of range-wide genetic structure across related, co-distributed rainforest trees reveals contrasting evolutionary histories. Aust J Bot 55:416-424

Rossetto M, Gross CL, Jones R, Hunter J (2004) The impact of clonality on an endangered tree (Elaeocarpus williamsianus) in a fragmented rainforest. Biol Conserv 117:33-39

Rossetto M, Kooyman RM (2005) The tension between dispersal and persistence regulates the current distribution of rare Palaeoendemic rain forest flora: a case study. J Ecol 93:906-917

Rymer PD, Sandiford M, Harris SA, Billingham MR, Boshier DH (2015) Remnant Pachira quinata pasture trees have greater opportunities to self and suffer reduced reproductive success due to inbreeding depression. Heredity 115:115-124

Sebbenn AM, Carvalho ACM, Freitas MLM, Moraes SMB, Gaino APSC, Da Silva JM et al. (2011) Low levels of realized seed and pollen gene flow and strong spatial genetic structure in a small, isolated and fragmented population of the tropical tree Copaifera langsdorffii desf. Heredity 106:134-145

Seidler TG, Plotkin JB (2006) Seed dispersal and spatial pattern in tropical trees. PLoS Biol 4:e344 
Silva CRS, Albuquerque PSB, Ervedosa FR, Mota JWS, Figueira A, Sebbenn AM (2011) Understanding the genetic diversity, spatial genetic structure and mating system at the hierarchical levels of fruits and individuals of a continuous Theobroma cacao population from the Brazilian Amazon. Heredity 106:973-985

Slatkin M (1987) Gene flow and the geographic structure of natural populations. Science 236:787-792

Sokal RR, Rohlf FJ (1995) Biometry: the principles of statistics in biological research. WH Freeman and Co, New York

Sork VL, Smouse PE (2006) Genetic analysis of landscape connectivity in tree populations. Landsc Ecol 21:821-836

Stacy EA, Hamrick JL, Nason JD, Hubbell SP, Foster RB, Condit R (1996) Pollen dispersal in low-density populations of three Neotropical tree species. Am Nat 148:275-298

Stockwell CA, Hendry AP, Kinnison MT (2003) Contemporary evolution meets conservation biology. Trends Ecol Evol 18:94-101

Tambarussi EV, Boshier D, Vencovsky R, Freitas MLM, Sebbenn AM (2015) Paternity analysis reveals significant isolation and near neighbor pollen dispersal in small Cariniana legalis Mart. Kuntze populations in the Brazilian Atlantic forest. Plant Ecol Evol 5:5588-5600

Tambarussi EV, Boshier D, Vencovsky R, Freitas MLM, Sebbenn AM (2017) Inbreeding depression from selfing and mating between relatives in the Neotropical tree Cariniana legalis Mart. Kuntze. Conserv Genet 18:225-234

Tani N, Tsumura Y, Kado T, Taguchi Y, Lee SL, Muhammad N et al. (2009) Paternity analysis-based inference of pollen dispersal patterns, male fecundity variation, and influence of flowering tree density and general flowering magnitude in two dipterocarp species. Ann Bot 104:1421-1434

Theim TJ, Shirk RY, Givnish TJ (2014) Spatial genetic structure in four understory Psychotria species (Rubiaceae) and implications for tropical forest diversity. Am J Bot 101:1189-1199

Thurlby KAG, Wilson PG, Sherwin WB, Connelly C, Rossetto M (2012) Reproductive bet-hedging in a rare yet widespread rainforest tree, Syzygium paniculatum (Myrtaceae). Aust Ecol 37:936-944

Vinson CC, Kanashiro M, Sebbenn AM, Williams CR, Harris SA, Boshier DH (2015) Long-term impacts of selective logging on two Amazonian tree species with contrasting ecological and reproductive characteristics: inferences from Eco-gene model simulations. Heredity 115:130-139

Wang J, Kang M, Huang H (2014) Long-distance pollen dispersal ensures genetic connectivity of the low-density tree species, Eurycorymbus cavaleriei, in a fragmented Karst forest landscape. Conserv Genet 15:1163-1172

Ward M, Dick CW, Gribel R, Lowe AJ (2005) To self, or not to self... A review of outcrossing and pollen-mediated gene flow in Neotropical trees. Heredity 95:246-254

Williams G, Adam P (2010). The flowering of Australia's rainforests: A plant and pollination miscellany. CSIRO Publishing

Young A, Boyle T, Brown T (1996) The population genetic consequences of habitat fragmentation for plants. Trends Ecol Evol 11:413-418

Younginger BS, Sirová D, Cruzan MB, Ballhorn DJ (2017) Is biomass a reliable estimate of plant fitness? Appl Plant Sci 5:1600094 